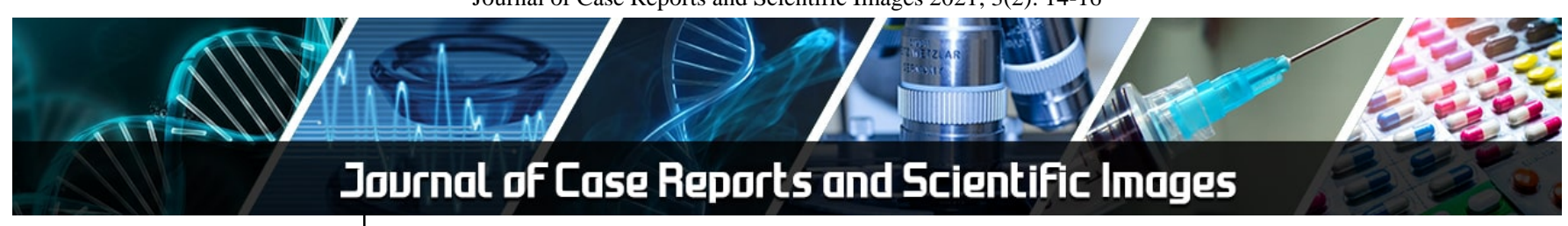

E-ISSN: 2708-0064

P-ISSN: 2708-0056

IJCRS 2021; 3(2): 14-16

www.allcasereports.com

Received: 13-06-2021

Accepted: 15-07-2021

Dr. Shilpi Srivastava

MD, Radiodiagnosis,

Saraswathi Institute of

Medical Sciences, Hapur,

Uttar Pradesh, India

Dr. Prabhat Saxena

DCH, Department of

Pediatrics, KGMC, Lucknow,

Uttar Pradesh, India

Dr. Subhash C Sylonia

MD, Radiodiagnosis,

Saraswathi Institute of

Medical Sciences, Hapur,

Uttar Pradesh, India

\section{Esophageal duplication Cyst, an unusual cause of recurrent chest infections \& stridor, missed as mimicking thymic shadow on chest radiographs}

\author{
Dr. Shilpi Srivastava, Dr. Prabhat Saxena and Dr. Subhash C Sylonia
}

DOI: https://doi.org/10.22271/27080056.2021.v3.i2a.32

\begin{abstract}
Background: Esophageal duplication cyst is an uncommon condition but, it is essential to be considered in the differential diagnosis of chronic cough and wheezing among young children. Surgery is indicated in symptomatic cyst, as early as possible to prevent complication and potential malignant transformation.

Aim- We reported this case, as knowledge of esophageal duplication cyst's clinical features, imaging findings and knowledge of their mimics may help radiologists \& clinicians to arrive at the correct diagnosis as earliest possible.

Imaging Findings: We reported a case of 9 year old male child, admitted with fever, cough \& decreased oral intake. Child was on oral treatment for last 8 days with no relief. His history was significant for recurrent episodes of cough and wheeze. Chest $\mathrm{X}$ ray showed a well defined homogenous, broad based opacity, projecting towards right mediastinum with smooth lateral borders, same as thymic shadow. CECT chest revealed a cystic paratracheal, paraesophageal mediastinal mass with fluid attenuation of 25 to $35 \mathrm{HU}$ in right mediastinum obstructing the right lateral wall of trachea and esophagus. Patient got operated, histopathological examination confirmed a diagnosis of esophageal duplication cyst.

Conclusion: Chest radiographs are initial Investigation of choice, however it is inconclusive, as it may mimic a thymic shadow on chest radiograph. CECT is the preferred imaging tool for the diagnosis of EDC. Usual approach is to surgically excise these lesions.
\end{abstract}

Keywords: Esophageal duplication cyst (EDC), CECT chest.

\section{Introduction}

Although, Esophageal duplication cyst (EDC) is an uncommon condition but, it is essential to be considered in the differential diagnosis of chronic cough and wheezing among young children. Esophageal duplication cysts are benign bronchopulmonary foregut malformations, estimated incidence reported is 1:8200 ${ }^{[1]}$. More common in male $(2: 1)^{[1]}$. Most common location of EDC is in right posterior mediastinum, $2 / 3^{\text {rd }}$ are located in lower esophagus \& remaining $1 / 3^{\text {rd }}$ located in middle or upper esophagus ${ }^{[2]}$. They may manifest themselves as separate masses along or in continuity with the native esophagus. Upto $80 \%$ of the esophageal duplication cysts are diagnosed in childhood and the majority of the young patients develop symptoms, while symptomatic cysts in adult age is very rare $(<7 \%){ }^{[3]}$. EDC characteristically exhibit clinical and radiological polymorphism. They pose a differential diagnostic problem as in our case. It may mimic a thymic shadow on chest radiograph. Surgery is indicated in symptomatiac cysts, as early as possible to prevent complications and potential malignant transformation ${ }^{[4]}$. Their definitive diagnosis is established primarily by histopathological examination of surgical specimen.

\section{Case Report}

We reported a case of 9 year old male child, who had admitted with continuous fever, cough \& decreased oral intake for 8 days. Child was on oral \& inhaled medications for last 8 days with no relief. On physical examination, child was afebrile, temp $98.8^{\circ} \mathrm{F}$, BP- 100/60 mm of $\mathrm{Hg}$, PR- 90/min, $\mathrm{SPO}_{2}$ 98\%, no respiratory distress, no recession, chest $\mathrm{B} / \mathrm{L}$ ronchi present, crepts present RT>LT. His blood investigations show Hb-11.9, TLC-7.79, Platelet -3.29, urine $\mathrm{R} / \mathrm{M}, \mathrm{H}_{1} \mathrm{~N}_{1}$, mantoux \& thyphoid test were negative, CRP was $24.69 \mathrm{mg} / \mathrm{dl}$. His history was significant for recurrent episodes of cough and intermittent wheeze which started at one year of age. There was no H/o rhinitis, noisy breathing, rashes, allergy, seasonal variations of episodes. There was H/o asthma in Grandfather \& nasal allergy in the father.
Dr. Shilpi Srivastava MD, Radiodiagnosis, Saraswathi Institute of Medical Sciences, Hapur, Uttar Pradesh, India 
Child was treated as a case of recurrent wheezing with bronchodilators and inhaled steroid. He was not on any regular medications. His symptoms used to resolve in each episode \& reoccur again after 3-4 weeks. He visited various health facilities \& in early childhood got many chest $\mathrm{X}$ rays. $\mathrm{X}$ rays were underdiagnosed each time as thymic shadow. Rest of the $\mathrm{X}$ ray findings used to come normal everytime. Presently as he get admitted with above mentioned complaints \& no relief on oral medications for last 8 days. A chest $\mathrm{X}$ ray was performed, showed a well defined homogenous, broad based opacity towards mediastinum with smooth lateral borders, seen well above the clavide, findings suggest a mediastinal mass, in addition to keeping the possibility of thymic shadow. In the view of excessive cough \& abnormal shadow in chest radiograph, CECT chest was done. CECT chest revealed a well circumscribed cystic mediastinal mass with mean attenuation value of 25 to 35 $\mathrm{HU}$, measuring $4.3 \times 4.1 \times 4 \mathrm{~cm}$ in right paratracheal location, abutting the right lateral wall of trachea and esophagus. It was seen extending from the level of thoracic inlet till the lower border of $\mathrm{D}_{3}$. No evidence of fat/haemorrhage/ enhancing component was seen within the lesion. CECT chest findings suggest cystic mediastinal mass. In the view of anatomical location, radiological findings \& clinical history the differential diagnosis of Bronchogenic cyst \& esophageal duplication cyst was made.

Paitent was treated in hospital on intravenous medications \& referred to paediatric surgeons where he got operated. Thoracoscopic excision of foregut duplication cyst was performed in semiprone position under GA. Cyst was indentified above the level of azygous vein and just lateral to the SVC and phrenic nerve. Overlying pleura incised with hook, cyst was dissected. It was sharing a common muscle wall with esophagus but not communicating. Most of the cyst excised, but on the esophagus mucosal excision was done. Haemostasis achieved, ICD left in situ \& port sites closed. On Postoperative day 1 he allowed orally, ICD removed on day 3. Post ICD removal chest $\mathrm{X}$ ray was normal. Child was afebrile, alert, accepting orally well, no abdominal distension, no vomiting, no difficulty in passing urine and stool, urine output was adequate, operation wound was healthy \& discharged in hemodynamically stable condition. His post op course was uneventful till date, patient is healthy \& asymptomatic.

Histopathological examination confirmed the diagnosis of esophageal duplication cyst. On gross examination it showed a single flattened cyst tissue piece measuring 4x3x2 $\mathrm{cm}$. On microscopic examination, cut section showed a cystic lesion having double layer of smooth muscle coat. Overlying musosa was squamous to ciliated epithelium. The lamina propria showed focal chronic inflammation with occassional lymphoid follicle, few mucus glands were seen underneath.

In our case, in chest radiographs of the child, imaging findings of mediastinal cyst (esophageal duplication cysts) were similar to a thymic shadow. So that his $\mathrm{X}$ rays were misinterpreted everytime. But presently, keeping in mind the patient's clinical history, no relief on medications, pliability of the normal thymus (that is not to produce any compressive effect) \& abnormal mediastinal shadowing in present chest radiograph, patient was subjected for CECT chest, that suggest the diagnosis of cystic paratracheal, paraesophageal mediastinal mass.

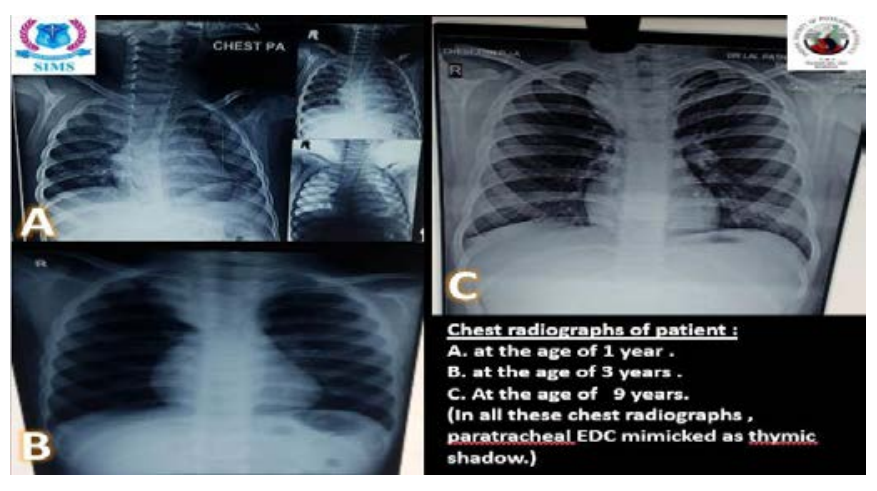

Fig 1: Chest radiograph of patient at different ages

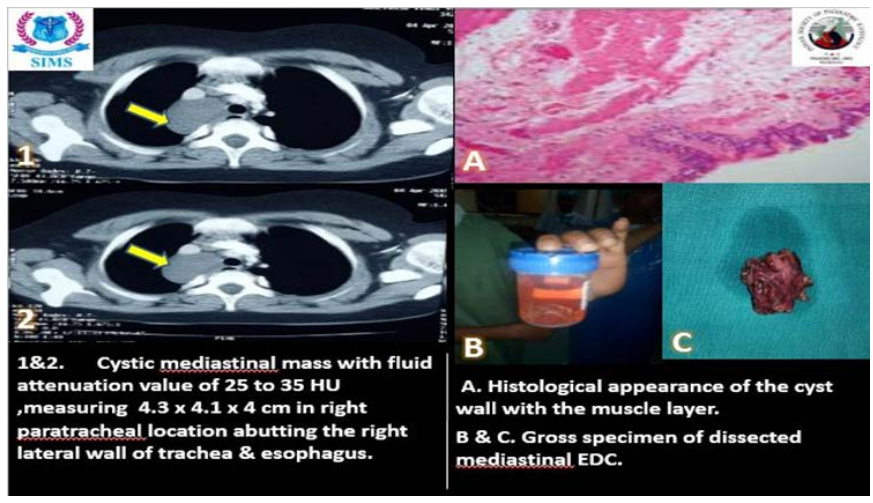

Fig 2: Gross specimen of dissected mediastinal EDC

\section{Discussion}

Foregut duplication cysts are categorized on the basis of their embryonic origin into esophageal, bronchogenic \& neuroenteric cyst ${ }^{[5]}$. Bronchogenic \& esophageal duplication cysts are thought to arise from abnormal budding of the embryonic foregut at 5-8 week gestation ${ }^{[6]}$. Of note $50-70 \%$ foregut duplication cysts are enterogenous while $7-15 \%$ of them are bronchogenic ${ }^{[7]}$. Foregut duplication cyst constitutes $6-15 \%$ of the primary mediastinal masses ${ }^{[8]}$. As well expected from the common embryonic origin, bronchogenic and esophageal duplication cysts can occur together.

Esophageal duplication cysts are the $2^{\text {nd }}$ most common enteric duplication cysts. Following small bowel duplication cyst it accounts for approx $10-15 \%$ of gastrointestinal duplication cysts ${ }^{[7]} .80 \%$ of these lesions are diagnosed in childhood with the majority being symptomatic [7, 9]. Esophageal cysts develop from aberrant elements of the esophageal wall. Simple cysts are duplication of the epithelium, whereas true esophageal duplications are duplication of the submucosa and the muscle wall without duplication of the epithelium.

Most of the esophageal duplication cysts are located in right posterior inferior mediastium. $2 / 3^{\text {rd }}$ of these lesions were found in the lower third of esophagus ${ }^{[2]}$ and remaining $1 / 3^{\text {rd }}$ located in upper \& middle esophagus. Diagnosis of EDC is difficult but should be thought of after excluding common causes of persistent or recurrent wheeze, distress, stridor, vomiting \& dysphagia. Upper esophageal duplication cyst can cause stridor or nonproductive cough, while cysts in the middle \& lower esophagus can cause dysphagia, epigastric discomfort, chest pain or vomiting $[10,11]$. Symptoms are caused by compression of surrounding structures. The larger the cyst, the greater the chances of it causing symptoms. No case could be found to the best of the knowledge which 
present with both respiratory symptoms \& feeding difficulties.

CECT/MRI is the preferred imaging as precise location, anatomy and nature of the lesion can be explained better, which will aid in surgery. Endoscopic ultrasound (EUS) is also an important diagnostic modality for evaluation of mediastinal cysts [12, 13]. It provides a good tool to characterize these lesions and distinguish them from bronchogenic cyst by the absence of cartilage, proximity to the esophagus and double muscle layer around them ${ }^{[14,15]}$. EUS will usually reveal an anechoic homogenous lesion with smooth margins in the submucosal wall. The muscularis propria of the lesion is continuous with the muscularis of the esophagus. It is important to consider the possibility of esophageal duplication even in patients with hypoechoic lesion or with heteroechoic lesion with an anechoic component, because the presence of pus, blood or thick contents may modify the EUS features and result in confusion with other soft tissue lesion like stromal tumours $[15,16]$. The differentials of esophageal duplication cysts include hydatid cyst, mullerian cyst, bronchogenic cysts, pericardial cysts or cystic degeneration of mediastinal tumour ${ }^{[17]}$.

Histopathological examination will be required for confirming the diagnosis, the criteria include

1) The cyst should be within or attached to esophageal wall.

2) It should be covered by 2 muscle layers.

3) The lining should be either squamous, columnar, cuboidal, ciliated or pseudostratified ${ }^{1}$.

Various complication may develop in it like haemorrhage, perforation, infection and malignant transformation. They may undergo peptic ulceration if lined by gastric tissue, which may lead to perforation or gastrointestinal bleeding. Malignancy may also occur, although the exact rate is uncertain $^{[16,18,19]}$.

Surgery is indicated in symptomatic cyst, as early as possible to prevent complications and potential malignant transformation ${ }^{[20]}$. Minimally invasive thoracosopic surgery are very successful depending upon the expertise and availability. Treatment in asymptomatic patient is controversial. Patient should be monitored for symptoms \& increase in the size of cyst. If the entire cyst is excised, recurrence is rare. Overall morbidity is low, most patients do well, both in the short term \& in the long term.

\section{Conclusion}

EDC is a very rare congenital malformation. Most of the patients remain asymptomatic, presentation as a respiratory illness has been seen in few case reports. Though uncommon but we concluded that EDC should be kept in differential diagnosis of recurrent chest infection/unexplained wheeze and stridor in children, when other common causes has been excluded. Chest radiographs are initial Investigation of choice, however it is inconclusive, as it may mimic a thymic shadow on chest radiograph. CECT is the preferred imaging tool for the diagnosis of EDC. Usual approach is to surgically excise these lesions.

\section{References}

1. Arbona JL, Fazzi JGF J. Mayoral congenital esophageal cyst: case report and review of literature. Am J gastroentuol 1984;79:177-182.

2. Bhatia V, Tajika M. A Rastogi upper gastrointestinal submucosal lesions - clinical and endosonographic evaluation and management. Trop Gastroentuo 2010;31:5-29.

3. Pisello F, Gerai G, Arnone E, Scivto A, Modica G, Sciume C. acute onset of esophageal duplication cyst in adult. Case report. G chir 2009;30(1-2):17-20.

4. Trojan J, Mousset S, Castrary WF, Hoepffrer M. An infected esophageal duplication cyst in a patient with non-hodgken's lymphoma mimicking persistent disease.

5. Diehl DL, Cheru Vattan R, Facktor MA et al. infection after endoscopic ultrasound- guided aspiration of mediastinal cysts. Intract cardiovase thoral surg. 2010;10:338-40.

6. Mobuhara KK, Goski YC, La quaglia MP et al. bronchogenic cyst and esophageal duplications: common origin and treatment. $\mathrm{T}$ Pediatr surg. 1997;32:1408-13.

7. Whitaker JA, Deffenbough LD, cooke AR. Esophageal duplication cyst. Case report. Am J Gastroenterol 1980;73:329-32.

8. Synder ME, luck SR, Hernandez $\mathrm{R}$ et al. Diagnostic dilemmas of mediastinal cysts. J Pediatr surg 1985;2:810-5.

9. Cevasco M, Menard MT, Bafford R et al. Acute infectious Pseudoaneurysm of the descending thoraric aorta and review of infectious aortitis. Vase endovascular surg. 2010;44:697-700.

10. Bavton DL, Kalz PO. Esophageal cyst as a cause of chronic cough. Chest 1984;86:150-2.

11. Meo EL, Watson DI, bessell JR. acute ruptured esophageal duplication cyst. Dis esophagus 2004;1:10911.

12. Bhasin DK, Rana SS, Rao C et al. Clinical presentation, radiological features, and endoscopic management of mediastinal pseudocysts: experience of a decade. Gatrointest endose 2012;76:1056-60.

13. Rana SS, Bhasin DK, Srivasaso B et al. Endoscopic ultrasound features of mediastinal tubercular lymphagenopathy. Hepatogasteroenhology 2011;58:819-23.

14. Wiechowska - Kozlowska A, Wurusch E, Mahewski M et al. esophageal duplication cysts: endosonographic findings in asymptomatic patients. World J gasteroenterol. 2012;18:1270-2.

15. Kuhlman JE, Fishma EK, Wang KP et al. Esophageal duplication cyst: CT and tracheoespohageal needle aspiration. AJR Am J Roentenal. 1985;145:531-2.

16. Peiper $\mathrm{M}$, Lambrecht $\mathrm{W}$, Kluth $\mathrm{D}$ et al. Bleeding esophageal duplication detected in utero. Ann Thorae surg. 1995;60:1790-1.

17. Gumus M, Onder A, Firat U et al. Hydatid cyst like intra-abdominal esophageal duplication cyst in an endemic region. Turk J gasteroenterol 2011;22:557-8.

18. Singh S, Lal P, Sikora SS et al. squamous cell carcinoma arising from a congenital duplication cyst of the esophagus in a young adult. D is esophagus. 2001;14:258-61.

19. Tapia RH, Write VA. Squamous cell carcinoma arising in a duplication cyst of the esophagus. Am J Gasteroentnol 1985;80:325-9.

20. Trojan J, Mousset hoepfiner S. An infected esophageal duplication cyst in a patient with non-hodgkin's lymphoma mimicking persistent disease. Dis esophagus. 2005;18(4):287-298. 